OPEN ACCESS

Edited by:

Dario Marchetti,

The Methodist Hospital Research

Institute, USA

Reviewed by:

Giuseppe Curigliano,

European Institute of Oncology,

Italy

Pei-Wen Hsiao,

Academia Sinica, Taiwan

*Correspondence:

Amir Goldkorn

agoldkor@med.usc.edu

Specialty section:

This article was submitted to

Molecular and Cellular Oncology,

a section of the journal

Frontiers in Oncology

Received: 31 August 2016

Accepted: 06 January 2017

Published: 27 January 2017

Citation:

Hugen CM, Zainfeld DE and Goldkorn A (2017) Circulating Tumor

Cells in Genitourinary Malignancies:

An Evolving Path to

Precision Medicine.

Front. Oncol. 7:6.

doi: 10.3389/fonc.2017.00006

\section{Circulating Tumor Cells in Genitourinary Malignancies: An Evolving Path to Precision Medicine}

\author{
Cory M. Hugen ${ }^{1}$, Daniel E. Zainfeld' ${ }^{1}$ and Amir Goldkorn ${ }^{2 *}$ \\ ${ }^{1}$ Keck School of Medicine and Norris Comprehensive Cancer Center, Urology, Los Angeles, CA, USA, ${ }^{2}$ Keck School of \\ Medicine and Norris Comprehensive Cancer Center, Medicine, Los Angeles, CA, USA
}

Precision medicine with molecularly directed therapeutics is rapidly expanding in all subspecialties of oncology. Molecular analysis and treatment monitoring require tumor tissue, but resections or biopsies are not always feasible due to tumor location, patient safety, and cost. Circulating tumor cells (CTCs) offer a safe, low-cost, and repeatable tissue source as an alternative to invasive biopsies. "Liquid biopsies" can be collected from a peripheral blood draw and analyzed to isolate, enumerate, and molecularly characterize CTCs. While there is deserved excitement surrounding new CTC technologies, studies are ongoing to determine whether these cells can provide reliable and accurate information about molecular drivers of cancer progression and inform treatment decisions. This review focuses on the current status of CTCs in genitourinary (GU) cancer. We will review currently used methodologies to isolate and detect CTCs, their use as predictive biomarkers, and highlight emerging research and applications of CTC analysis in GU malignancies.

Keywords: circulating tumor cells, bladder cancer, prostate cancer, liquid biopsy, molecular characterization

\section{INTRODUCTION}

Circulating tumor cells (CTCs) are cancer cells that are shed from a primary or metastatic tumor site, traffic through the vasculature, and may establish distant metastasis. CTCs were first reported as far back as the late 1800s: Ashworth detected the cells in blood drawn from the saphenous vein and postulated that they would be identical to the primary tumor (1). However, CTCs began to make a significant scientific and clinical impact on cancer only in the recent decade, enabled by technological advancements that allow improved detection and isolation of these rare cells from blood.

Circulating tumor cells have been identified and isolated from patients with virtually every type of solid malignancy. Cancers of the prostate, bladder, and kidney comprise 3 of 10 most common primary malignancies diagnosed in the United States (2), and CTCs have been isolated from each of these malignancies. While numerous studies have focused on CTCs in patients with prostate cancer, few studies have focused on other genitourinary (GU) malignancies including bladder, kidney, and testicular.

In this review, we will focus on CTCs with respect to their role in GU malignancies. We will first provide a brief synopsis highlighting some of the currently available technologies used to identify and recover CTCs. We will then review how CTCs are being developed clinically as prognostic and predictive biomarkers in GU malignancies. Finally, we will address how CTCs are being leveraged to elucidate disease biology by identifying key mechanisms of resistance and progression. 


\section{BRIEF SYNOPSIS OF TECHNOLOGIES}

Several different methods have been developed to isolate and analyze CTCs. Each detection strategy exploits a different physical property of the cells in order to separate them from the billions of red blood cells and millions of white blood cells (WBC) also present in a standard $7.5 \mathrm{ml}$ sample of human blood (method overview in Figure 1).

The most clinically established method to isolate CTCs is immunoaffinity (3). This method employs magnetic beads attached to antibodies directed at specific cell surface antigens present on CTCs, most commonly epithelial cell adhesion molecule (EpCAM). After the antibodies bind to their target, a magnet is used to separate these cells from background cells. The most heavily studied immunoaffinity device has been the CellSearch $^{\circledast}$ platform (developed by Janssen Diagnostics, LLC and recently acquired by Menarini-Silicon Biosytems). This FDAcleared system uses ferrofluid nanoparticles attached to antibodies directed against EpCAM on CTCs to separate these cells from other cells present in the buffy coat following centrifugation of whole blood. Once separated, these cells are then stained with fluorophore-labeled antibodies directed against cytokeratin (CK), CD45 (a leukocyte-specific cell marker), and the 4',6-diamidino2-phenylindole (DAPI) nuclear stain. Cells that stain EpCAM+, $\mathrm{CK}+, \mathrm{CD} 45-$, with DAPI+ are considered CTCs (4).

Another example of a system-utilizing immunoaffinity is the CTC-chip platform. The CTC-chip has thousands of small posts embedded with EpCAM antibodies. Blood flows through the chip and cells expressing EpCAM on their surface bind to the posts and are separated from non-EpCAM expressing cells $(5,6)$. The CTC-iChip uses immunoaffinity combined with microfluidics to isolate CTCs but does not rely on EpCAM labeling. This device is composed of two chips that first separate nucleated cells present in whole blood from non-nucleated cells using deterministic lateral displacement which separates cells via size-based deflection.
The WBCs are also tagged with CD45 and CD66b (a more specific target of granulocytes) antibodies during this phase. The second step uses inertial focusing and magnetophoresis to separate the remaining nucleated cells based on their magnetic bead load, which separates CTCs from WBCs (7).

Immunoaffinity-based techniques have advantages as well as limitations: the most notable strength of these approaches is their extensive validation to date. CellSearch has by far been the most commonly used method in large clinical trials across malignancies, where it has been validated repeatedly and become a de facto "gold standard" to which emerging technologies are compared. If a tumor-specific cell surface marker is available for a given malignancy, immunoaffinity can serve as a sensitive and specific strategy for enriching cancer cells from the blood. Conversely, the main limitation of immunoaffinitybased techniques is that such a sensitive and specific marker often is not available. EpCAM-based systems may fail to identify subsets of cells undergoing epithelial-to-mesenchymal transition (EMT). This phenotypic transformation is thought to be necessary for cells to migrate from the primary tumor location and metastasize. These cells often downregulate EpCAM antigen and express mesenchymal antigens instead, thus reducing the sensitivity of an EpCAM-based approach. Moreover, EpCAM is not a CTC-specific marker per se, but rather a marker of all epithelial cells; thus, it is possible that some CTCs enriched in this manner may not be tumor cells but rather benign epithelial cells, thus reducing the specificity of EpCAM-based enrichment.

A second broad methodology used to isolate CTCs is based on size and deformability, as CTCs are typically larger and more rigid than WBCs. Many groups have described variations of this technique, and some examples include use of a Parylene-C slot microfilter (8), a porous polycarbonate membrane (9), a resettable trap with adjustable aperture (10), and a polycarbonate track-etch-type membrane with cylindrical pores (11).

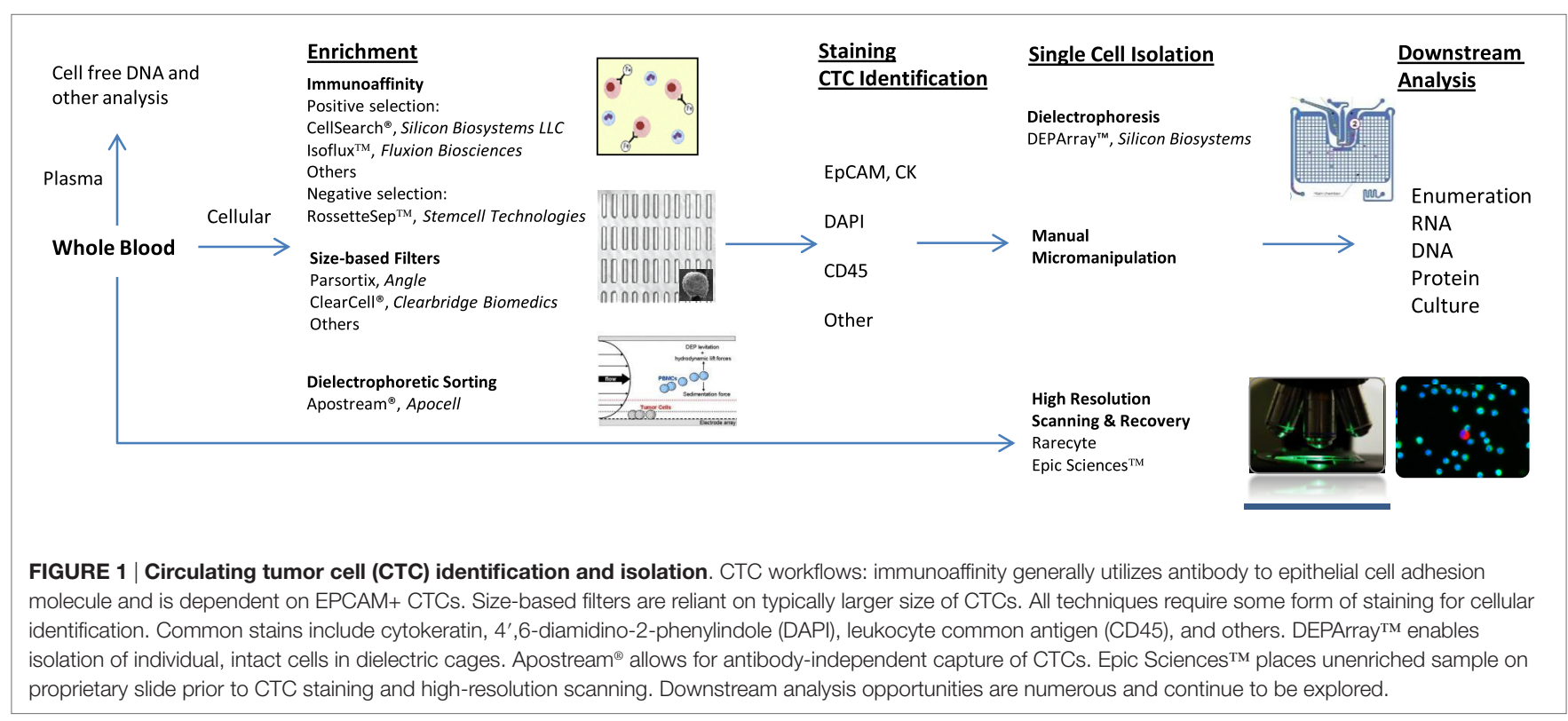


Size-based techniques offer several pros and cons: one advantage compared with immunoaffinity-based technologies is that cell isolation does not rely on cell surface markers, allowing for the capture of cells that do not express the platform-specific antigen. Another advantage, compared with CellSearch ${ }^{\circledR}$, is that cells do not require fixation and therefore live cells can be captured and further manipulated. On the other hand, size-based platforms have limited sensitivity and specificity, because they may retain large cells that are not CTCs or fail to capture smaller CTCs. Additionally, once these cells are captured, they require additional positive identification steps (e.g., immunofluorescent staining) (3).

Several other methodologies exist to capture and identify CTCs based on a variety of cellular features. Examples include the DEPArray ${ }^{\mathrm{TM}}$ (Silicon Biosystems, Italy) system, which uses a microfluidic cartridge with controllable electrodes to create dielectric cages around cells for isolation and recovery (12). Another dielectric separation-based system is ApoStream ${ }^{\circledR}$ (Apocell Inc., Houston, TX, USA), which also exploits the differences in dielectric properties between CTCs and peripheral blood mononuclear cells to focus and separate cells (13). Others have isolated CTCs based on their ability to invade collagenous matrices, or using atomic force microscopy to determine the nanomechanical properties of CTCs such as elasticity, deformation, and adhesion to identify CTCs $(14,15)$. All of these approaches offer unique advantages and disadvantages based on sensitivity, specificity, speed, and reproducibility of workflow, and compatibility with fixed vs live cells. In-depth discussion of each is beyond the scope of this review.

More recently, two platforms have eschewed enrichment altogether and instead take a "no cell left behind" approach using rapid high-resolution scanning and automated detection algorithms to identify CTCs. Epic ${ }^{\text {TM }}$ (Epic Sciences, San Diego, CA, USA) utilizes immunofluorescent staining (CK, DAPI, CD45, as well as one or two additional antibodies) of nucleated cells spread as a monolayer on proprietary slides. These slides are then scanned using a whole slide fluorescent microscope. A computerized algorithm then incorporates immunofluorescent and morphologic features to identify candidate CTCs (16). Rarecyte ${ }^{\mathrm{TM}}$ (RareCyte, Seattle, WA, USA) spreads the buffy coat on slides and then performs automated multiplex imaging with scanning algorithms to detect and rank potential CTCs (17). Advantages of these systems include rapid detection, automation, and the ability to map and characterize the entire complement of circulating cells, regardless of size or antigen expression. However, the cells are fixed to a solid matrix that somewhat limits manipulation, precludes live cell assays, and allows recovery of most but not all DNA and RNA for analysis.

\section{CLINICAL DEVELOPMENT}

\section{Prostate Cancer}

The majority of CTC research and clinical development to date in GU malignancies has been undertaken in patients with prostate cancer, and most of these studies have used CTC enumeration as their clinical end point. Beyond enumeration, recent studies have begun to molecularly characterize isolated CTCs and to study their nanomechanical properties as enabling downstream technologies continue to develop. Prostate cancer CTC enumeration studies have been performed in the full spectrum of disease states, from localized prostate cancer $(18,19)$, to metastatic hormone-sensitive prostate cancer (mHSPC) (20-22), to

TABLE 1 | Selected prospective circulating tumor cell (CTC) studies in prostate cancer.

Localized prostate cancer

Davis $\quad 97$ patients with localized prostate cancer evaluated for CTCs prior to planned prostatectomy as well as various intervals following surgery. CTCs

et al. (18) detected in $21 \%$ of patients and did not correlate with tumar volume, pathological stage, or Gleason score

Pal Sample blood from 35 patients with high-risk localized prostate cancer collected prior to treatment. CTCs identified in $49 \%$ prior to surgery but no

et al. (19) correlation between CTC count and biochemical recurrence identified at 1 year follow-up

Metastatic hormone-sensitive prostate cancer (mHSPC)

Okegawa SO patients identified prior to initiation of hormonal therapy. CTC counts ranged from 0 to $222 / 7.5 \mathrm{ml}$ blood, with 44 patients having 5 or more CTCs.

et al. (21) More than 5 CTCs median androgen deprivation therapy (ADT) responsiveness 17 months vs 32 for those with $<5$ CTCs

Goldkorn CTCs detectable in 78/211 (37\%) patients in CTC enumeration corollary to SWOG 1216 (ADT plus bicalutamide or orteronel in setting of MHSPC).

et al. (35) Baseline CTC detection associated with higher prostate-specific antigen (PSA), extensive disease, and bony metastasis. Trial ongoing including molecular characterization

Metastatic castrate-resistant prostate cancer (mCRPC)

de Bono Evaluation of 231 patients prior to initiating new line chemotherapy and monthly thereafter. Patients stratified to favorable $(<5)$ vs unfavorable $(>5)$ CTC

et al. (24) counts. CTC count superior to PSA for predicting OS (11.5 vs 21.7 months) among those with unfavorable CTC count

Scher $\quad 147$ eligible patients from IMMC38 trial identified prior to initiation of chemotherapy. Changes in CTC number strongly associated with risk of death at 4 ,

et al. (25) 8, and 12 weeks after treatment suggesting CTC number as a continuous variable useful for disease status monitoring

Goldkorn Prognostic value of CTCs for overall survival and disease response assessed in SWOG 0421(docetaxel plus prednisone with or without atrasentan).

et al. $(29,30)$ Baseline CTC counts found to be prognostic of overall survival and rising CTCs at 3 weeks predicted worse OS. In addition, telomerase activity in CTCs captured on Parylene-C microfilter found prognostic of overall survival (19 vs 12 months) in men with 6-54 CTCs/7.5 ml

Antonarakis RT-PCR identified androgen receptor splice variant 7 (AR-V7) splice variant in CTCs of patients receiving enzalutamide or abiraterone for mCRPC. AR-V7 et al. (39) in CTCs associated with lower PSA response, shorter PFS, and decreased OS 
metastatic castrate-resistant prostate cancer (mCRPC) (23-28). In the following sections, we will review studies in each of these areas (selected prospective studies highlighted in Table 1).

\section{Castrate-Resistant Prostate Cancer}

Therapeutic options for mCRPC have expanded markedly over the past decade and now include several new hormonal therapies, chemotherapies, a vaccine, and a radiopharmaceutical. Informative new biomarkers may help guide choice of therapy. In one of the first published studies, Danila et al. (25) enumerated CTCs from 120 patients with mCRPC using the CellSearch ${ }^{\circledR}$ platform and showed that CTC enumeration, when treated as a continuous variable, was inversely associated with overall survival. The combination of CTC enumeration, prostate-specific antigen (PSA), and albumin was found to be a better predictor of survival than any of these individual variables alone. CTC counts were higher in patients with bone vs soft-tissue metastasis and in those who received prior cytotoxic chemotherapy.

In a seminal mCRPC study by de Bono et al. (24), CellSearch ${ }^{\circledR}$ was used to enumerate CTCs in 276 patients with metastatic CRPC treated with various hormonal agents and chemotherapies. CTCs were detected in 231 patients, and patients with $\geq 5$ CTCs had significantly worse overall survival than patients with $<5$ CTCs (11.5 vs 21.7 months, HR 3.3, $p<0.0001$ ). This CTC cutoff value was also a better predictor of overall survival than PSA at 1 year. Interestingly, patients whose CTCs increased from $<5$ at baseline to $\geq 5$ at subsequent time points had worse outcomes, whereas patients who converted from $\geq 5$ to $<5$ CTCs had better outcomes than patients who remained stable. Goldkorn et al. (29) confirmed this CTC cut point in a prospective randomized phase III study, SWOG 0421. Patients with mCRPC were treated with docetaxel \pm atrasentan, and those with baseline CTC counts of $\geq 5$ vs $<5$ had median overall survival differences of 13 vs 26 months, respectively (HR, 2.74, 95\% CI, 1.72-4.37, $p<0.001$ ). Moreover, any increase in the CTC count after cycle 1 of therapy (at 3 weeks from baseline) was associated with reduced overall survival (HR, 2.55, 95\% CI, 1.04-6.24, $p=0.041)$. In a parallel study, Goldkorn et al. (30) evaluated telomerase activity in CTCs isolated from patients enrolled in SWOG 0421 and found that this cancer marker predicted overall survival in patients with CTC counts $\geq 5$. While de Bono and Goldkorn arrived at a cutoff of $\geq 5$ or $<5$ CTCs, Goodman et al. (23) performed threshold analysis from 100 patients with $\mathrm{mCRPC}$ and found that a CTC count of 4 was the optimal cutoff that best correlated with overall survival.

In a reanalysis of the 231-patient IMMC38 cohort described earlier (24), Scher et al. (26) found that dynamic CTC enumeration monitoring at predefined "landmark" time points could be used to monitor disease status. CTC counts of $\geq 5$ vs $<5$ at 4,8 , and 12 weeks following initiation of chemotherapy were associated with risk of death from prostate cancer, and CTC counts analyzed as a continuous variable (rather than specific cut points) also correlated with outcome.

A separate study by the same group (31) specifically evaluated CTC enumeration as a surrogate for overall survival. This was a secondary objective of COU-AA-301, a multinational, randomized double-blind phase III trial of abiraterone acetate plus prednisone vs prednisone alone in patients with metastatic CRPC who were previously treated with docetaxel. CTC enumeration combined with lactate dehydrogenase values met the Prentice criteria for surrogacy in a predictive marker. Such fully validated surrogate biomarkers have the potential to shorten drug development times and potentially guide treatment choices, thus minimizing morbidity from non-efficacious treatment at an earlier time point and maximizing the potential therapeutic efficacy from another agent.

\section{Hormone-Sensitive Prostate Cancer}

Circulating tumor cell analysis may prove useful in mHSPC as well, especially given recent studies demonstrating the benefit of combining hormonal therapy with chemotherapy $(32,33)$. Yu et al. (34) performed a corollary study as part of SWOG S0925, a randomized phase II trial of androgen deprivation therapy (ADT) combined with the IGF1 antibody cixutumumab vs ADT alone in patients with metastatic HSPC. They showed that baseline CTC enumeration categories of $0,1-4$, and $\geq 5$ for 39 evaluable patients was associated with PSA categories of $\leq 0.2,>0.2$ to $\leq 4.0$, and $>4.0$ at 28 weeks, $p=0.036$. Of note, $16(41 \%)$ patients had undetectable CTC values at baseline. Goodman et al. (20) evaluated multiple clinical variables including CTC enumeration in 33 patients with mHSPC and demonstrated that only baseline CTC count was independently prognostic of progression to mCRPC. They found that $\geq 3$ vs $<3$ was the optimal enumeration cutoff and this predicted a shortened time to MCRPC.

Another study (21) demonstrated that a baseline cutoff of 5 CTCs in a cohort of 80 patients with $\mathrm{mHSPC}$ was an independent predictor of duration of ADT responsiveness (17 vs 32 months, $p=0.007$ ). Furthermore, baseline PSA value was not a predictor of responsiveness; however, nadir PSA was a predictor. Additionally, a change in CTC count while on ADT was associated with treatment response duration: response-free rates for patients with CTC counts $\geq 5$ vs $<5$ at all time points was 32 vs 12 months $(p<0.001)$ and for patients with $\geq 5$ baseline CTC count who decreased to $<5$ during treatment it was 26 vs 12 months $(p=0.038)$. These results suggest that with additional validation, dynamic monitoring of CTC counts in HSPC may potentially be used as a clinical end point to guide changes in treatment strategy at an earlier point, possibly with improved outcomes.

Preliminary results of CTC studies in SWOG S1216, a randomized prospective phase III trial of MHSPC patients randomized to ADT in combination with either bicalutamide or orteronel, were recently presented at the 2016 American Society of Clinical Oncology meeting. Goldkorn et al. (35) demonstrated that CTCs were detectable in 78 of 211 (37\%) of evaluable samples, and detection rates were impacted by whether patients were treatment naïe ( $41 \%$ detection) or had already initiated hormonal therapy (29\% detection) at time of baseline draw, $p=0.01$. Additionally, baseline CTC detection was associated with higher PSA $(p=0.03)$, presence of extensive disease $(p<0.001)$, and bony metastasis $(p=0.05)$. Collectively, these enumeration studies are establishing an association between baseline CTC counts and other baseline prognostic factors, as well as with time to progression to $\mathrm{mCRPC}$. 


\section{Localized Disease}

The majority of studies have focused on metastatic disease based on the expectation of finding more CTCs with greater disease burden. However, several studies have evaluated CTCs in the context of localized prostate cancer with the goal of predicting recurrence after local definitive therapy. Pal et al. (19) collected blood from 35 patients with high-risk localized prostate cancer and evaluated using CellSearch ${ }^{\circledR}$ to discover whether CTCs from this group expressed any mesenchymal cell markers that could indicate that these cells were undergoing EMT. Blood was collected 2 weeks prior to radical prostatectomy, at the time of surgery, and 1 and 3 months following surgery and enriched CTCs were stained for the mesenchymal markers CD133 and E-cadherin. CTCs were detected in $49 \%$ of the 35 enrolled patients prior to surgery, and the percentages of CD133 and E-cadherin-positive CTC fragments were significantly higher in patients with biochemical recurrence at 1 year ( $p=0.028$ and 0.006 , respectively). This detection rate is similar to the $52 \%$ detection rate noted by Kolostova et al. (9) in clinically localized prostate cancer.

Davis et al. (18) used CellSearch ${ }^{\circledR}$ preoperatively in 97 patients with clinically localized prostate cancer and detected CTCs in $21 \%$ of patients. Interestingly, they also detected CTCs in $20 \%$ of the control group who had a negative extended-core prostate biopsy indicative of the inherent difficulties in CTC identification, particularly when greater volumes of blood $(30 \mathrm{ml}$ in this study) are utilized increasing the potential inclusion of benign epithelial cells in the blood of healthy individuals. The authors suggest that CTCs might be used to determine which patients should undergo a repeat prostate biopsy following negative initial biopsy, an approach that warrants further investigation.

In the only systematic review and meta-analysis we identified in this field, Ma et al. (36) concluded that CTC counts are associated with overall survival and disease-free survival in patients with localized prostate cancer.

\section{Molecular Characterization}

As the sociologist William Bruce Cameron wrote: "not everything that can be counted counts, and not everything that counts can be counted"-CTC enumeration studies have provided a proof of concept for the detection and isolation of CTCs in humans, but the field is quickly moving beyond enumeration alone, with major efforts now focused on the molecular characterization of CTCs. Such studies aim to identify molecular drivers of treatment resistance or disease progression that can be used to monitor disease in real time and to direct personalized therapeutics.

\section{Immunofluorescent Staining}

As described earlier, the majority of CTC studies to date have employed immunofluorescence to some degree, whether simply to identify CTCs (EpCAM, CK, DAPI, CD45) or to characterize them (CD133, E-cadherin). Other examples include fluorescence in situ hybridation (FISH) (37) to detect ERG rearrangements, PTEN loss, and AR copy numbers (38). Antonarakis et al. (39) investigated androgen receptor splice variant 7 (AR-V7) in CTCs. The Alere ${ }^{\mathrm{TM}}$ CTC AdnaTest (Alere Inc., San Diego, CA, USA) was used to enrich CTCs for real-time PCR detection of AR-V7 and full-length androgen receptor (AR). Presence of AR-V7 in CTCs was associated with resistance to abiraterone and enzalutamide. This work was confirmed and extended recently by Scher et al. who obtained blood samples from men with mCRPC undergoing a change in systemic therapy due to progressive disease and identified CTCs using the EPIC Sciences platform. AR-V7 presence detected by immunofluorescent staining was predictive of poor response to AR signaling inhibitors and improved response to taxane therapy, suggesting a potential role for CTC evaluation in directing advanced prostate cancer therapy (40). At least four separate groups have evaluated AR expression in CTCs. Miyamoto et al. (41) showed that patients with metastatic prostate cancer initiating ADT had significantly different AR staining patterns compared with metastatic CRPC patients initiating second-line therapies for CRPC. Reyes et al. used fluorescence-activated cell sorting (FACS) and ImageStreamX to produce real-time highresolution images of cells and demonstrated that AR expression was increased in patients with prior exposure to abiraterone and associated with increased Ki-67, a known cellular proliferation marker (42). On the other hand, Crespo et al. isolated CTCs using CellSearch ${ }^{\circledR}$ and then used FISH to demonstrate that AR expression in CTCs was unchanged in patients treated with enzalutamide or abiraterone, confirming these findings in tissue samples (43). Finally, Darshan et al. demonstrated via immunofluorescence that AR localization in the CTC cytoplasm vs nucleus was associated with treatment response to chemotherapy (44). Therefore, monitoring CTC AR subcellular localization might be a useful clinical parameter for patients being treated with taxane based chemotherapy.

\section{DNA/RNA Analysis}

Increasingly, targeted and high-throughput methods are applied to amplified genetic material from rare cells captured from blood. Stott et al. (6) used CTC-chip followed by on-chip lysis to isolate RNA for RT-PCR evaluation of TMPRSS2-ERG translocation in metastatic patients to further the molecular characterization of prostate cancer CTCs. Punnoose et al. (45) used the Epic Sciences platform to identify CTCs and found that PTEN status in CTCs correlated with PTEN status in patient-matched CRPC tissue and that loss of PTEN in CTCs was associated with worse clinical outcomes. Miyamoto et al. (46) used CTC-iChip to isolate 77 CTCs from patients with prostate cancer. These cells were micromanipulated, and the RNA content was extracted for amplification and next-generation sequencing. Considerable heterogeneity existed between individual CTCs with regard to expression of AR mutations and splicing variants-even between cells isolated from the same patient. Non-canonical Wnt5a was found to play an important role in overcoming the antiproliferative effect of AR inhibition. Jiang et al. (47) performed whole-genome sequencing on CTCs of patients with advanced prostate cancer by combining the NanoVelcro CTC-chip with laser capture microdissection to identify shared genomic alterations between CTCs and tumor tissues including structural variants in PTEN, RB1, and BRCA2. Similarly, Lohr et al. (48) performed whole-exome sequencing on CTCs isolated from patients with metastatic prostate cancer as well as matched metastatic and primary tumor. 51/73 (70\%) of CTC mutations were observed in matched tissue. In addition, 90 and $73 \%$ of 10 early-trunk and 56 metastatic-trunk mutations, 
respectively, found in the non-CTC tumor sample were also identified in CTC exomes.

An ongoing study embedded in a phase III prospective clinical trial (SWOG 1216) employs multiparametric CTC profiling to illuminate mechanisms of androgen therapy resistance over time. CTCs are not only being enumerated but also enriched for targeted sequencing (Liquid Biopsy platform, Cynvenio) as well as recovered for gene expression analysis (DEPArray platform, Silicon Biosystems). Studies such as this will ultimately contribute to more informed and effective therapy selection in the mHSPC disease state.

\section{CTC Culture}

Expansion of CTCs in vitro or in mouse avatar models holds potential for yielding large numbers of sustainable cells for molecular analysis and functional assays (e.g., drug sensitivity). This approach has met with some success in small cell lung cancer (49) and breast cancer (50). Unfortunately, experience has been more limited in prostate cancer, perhaps due to underlying differences in the biologies of these tumors, or due to lower abundance of recoverable CTCs. In one notable success, Gao et al. (51) were able to generate an organoid from CTCs isolated from a patient with metastatic prostate cancer. Whole-exome DNA sequencing demonstrated that this organoid expressed many of the same mutations present in archived formalin-fixed paraffin-embedded lymph node metastasis, but also with a few additional mutations. The authors suggest that these additional mutations may have been acquired during the transition from hormone-sensitive to castrate-resistant disease. Likewise, Vidal et al. successfully established CTC-derived xenografts in order to examine the role of GATA2 in regulating prostate cancer progression and chemotherapy resistance. CD45-negative cells were isolated from the blood of CRPC patients after separation by Ficoll gradient using FACS and subsequently implanted into NSG mice demonstrating potential utilities of these techniques (52).

Another group used the MetaCell ${ }^{\circledR}$ system (MetaCell s.r.o., Ostrava, Czech Republic) to isolate viable intact CTCs. This system uses a porous polycarbonate membrane to isolate cells based on size, successfully detecting CTCs at a high rate, 25/39 (64\%) of patients with muscle-invasive bladder cancer. They then successfully separated and cultured those cells in vitro in patients with prostate (9) and bladder cancer (53). Despite these encouraging findings, culturing CTCs from patients with GU cancers continues to be highly technically challenging, and multiple groups continue to work to develop improved methods. Ultimately, validation of such methods would require reliable culture techniques that could offer clinical utility for a significant portion of patients, and confidence that cultured CTCs closely represent the underlying molecular phenotype of patients' disease.

\section{Bladder Cancer}

To date, the majority of GU CTC research has been conducted in prostate cancer, probably due to its prevalence, the availability of large trial cohorts, and the presence of known molecular markers. All of these are present to a lesser degree in bladder cancer; nevertheless, as technologies improve and new treatments (e.g., immune checkpoint inhibitors) become available in bladder cancer, growing efforts are now invested in liquid biopsy and CTC studies in this disease.

\section{Metastatic Disease}

Gallagher et al. (54) used CellSearch ${ }^{\circledR}$ to enrich CTCs from 33 patients with metastatic urothelial cell carcinoma (UCC) and detected CTCs in 14/33 (44\%) of patients. Median CTC count in patients with two or more sites of metastasis was 3.5 vs 0 in patients with one metastatic site $(p=0.04)$. Okegawa et al. (55) used CellSearch ${ }^{\circledR}$ to enumerate CTCs in patients with bladder cancer. CTCs were detected in 11/20 (55\%) patients with metastatic bladder cancer and in $0 / 16$ patients with non-metastatic UCC. Similarly, Naoe and colleagues (56) reported a 57\% (8/14) detection rate in patients with metastatic disease. While detection rates do appear to correlate generally with disease state, the true CTC positivity may be impacted by variable EpCAM expression that may limit detection in these immunoaffinity-based studies. Flaig et al. (57) used the CellSearch ${ }^{\circledR}$ platform and detected $\geq 1$ CTC in 5/30 of patients with localized and 7/14 of patients with metastatic UCC. They also performed FISH using the UroVysion (Abbott Molecular, Des Plaines, IL, USA) probe set on 18 unique samples collected from the CellSearch ${ }^{\circledR}$ cartridge looking for DNA copy number variation (CNV). Nine of these samples were collected from patients with detectable CTCs and CNV was detected in five samples. None of the nine samples collected from patients without CTCs had CNV. All patients with metastatic disease and detectable CTCs were dead at $<1$ year while only 3/7 patients with metastases but without detectable CTCs were deceased at $<1$ year.

While detection rates do appear to correlate generally with disease state, the true CTC positivity may be impacted by variable EpCAM expression that may limit detection in these immunoaffinity-based studies. Using the Epic Sciences platform including immunofluorescent staining and algorithmic scanning, Anantharaman et al. (58) examined blood samples from patients with metastatic bladder cancer and detected CTCs in 20/25 (80\%) patients. $\mathrm{CK}^{-}$CTCs were present in 14/25 (56\%). Programed death-ligand 1 expression was found in both $\mathrm{CK}^{+}$and $\mathrm{CK}^{-}$cells and was associated with decreased overall survival. This study illustrates how high content imaging without enrichment may identify and characterize additional CTC subpopulations and help to guide therapy.

\section{Localized Disease}

Gazzaniga et al. (59) collected blood samples from 102 patients with T1G3 UCC prior to undergoing transurethral resection of bladder tumor. Using the CellSearch ${ }^{\circledR}$ platform, CTCs were detected in $20 \%$ of patients and their presence was associated with time-to-first recurrence, progression-free survival, and the development of distant metastasis. In an earlier report from this same group on 44 patients with non-muscle-invasive bladder cancer, CTCs were detected in 8/44 (18\%) of patients, and their presence was associated with higher tumor stage and the presence of carcinoma in situ (60).

Circulating tumor cell enumeration has also been studied in patients undergoing radical cystectomy. Guzzo et al. (61) detected CTCs in 9/43 (21\%) of patients undergoing radical cystectomy 
for clinically localized disease. The presence of detectable CTCs was not associated with extravesical tumor staging on final pathology. Rink et al. (62) collected blood from 100 patients with non-metastatic UCC treated with radical cystectomy. They detected CTCs using CellSearch ${ }^{\circledR}$ in 23 patients and reported that patients with detectable CTCs had worse recurrence-free survival, cancer-specific survival, and overall survival. They also stained for HER2 expression in the primary tumor, CTCs, and lymph nodes. Of the 22 CTC positive samples evaluated, HER2 expression was concordant with the primary tumor in 14 (64\%) cases. For five cases with detectable CTCs and metastatic lymph nodes, there was 100\% HER2 concordance rate (all stained negative).

Alva et al. (63) used the Isoflux ${ }^{\mathrm{TM}}$ immunomagnetic enrichment platform to detect CTCs in patients with UCCand compared their results to CellSearch $^{\circledR}$, finding improved CTC identification capacity. >10 CTCs was predictive of unfavorable pathology (pT1 or greater) from radical cystectomy following neoadjuvant chemotherapy (89\% PPV) while CTC enumeration $<10$ was predictive of favorable pathology (57\% NPV). In addition, they were able to detect somatic variants from 4/8 samples using next-generation sequencing from spike in samples. Sensitivity and specificity in the identification of CTCs using this platform will ultimately require further evaluation in the context of larger prospective cohorts. However, the detection of single-nucleotide variants from enriched cells provide promising genomic results and exemplify the potential of expanded studies examining single-nucleotide variants from CTCs, primary tumors, and metastases to better elucidate clonal disease progression in bladder cancer.

An ongoing study in a prospective multicenter clinical trial setting is in SWOG S1314, a randomized phase II testing a gene panel derived by co-expression extrapolation (COXEN) - as a predictive biomarker of response to neoadjuvant chemotherapy for localized, muscle-invasive bladder cancer. The primary aim of this study is to determine whether the COXEN score derived from CTC RNA can predict treatment response to neoadjuvant chemotherapy in a manner similar to RNA from bladder tumor biopsy. Collectively, these studies in locally advanced and metastatic bladder cancer aim to leverage improved recovery and amplification techniques to ultimately predict outcome and improve therapy selection.

\section{Kidney and Testis}

Few studies have been conducted evaluating CTCs in either kidney (64-66) or testis cancer (67), and most have focused on CTC enumeration. Nel et al. (64) studied CTCs in metastatic renal cell carcinoma patients using multiparameter immunofluorescence microscopy and detected subtypes of CTCs consistent with epithelial, mesenchymal, and stem cell-like characteristics. Bluemke et al. (65) detected CTCs in 81 (53\%) of 154 patients with renal cell carcinoma using autoMACS ${ }^{\circledR}$, an immunomagnetic-based platform. They reported that CTC detection was associated with positive lymph nodes $(p<0.001)$, synchronous metastases $(p=0.014)$, and in multivariate Cox regression analysis, CTCs were associated with overall survival (RR, 2.3, $p=0.048)$. An interesting study from Nastaly et al. (67) evaluated CTC enrichment from peripheral blood as well as testicular vein blood in patients with testicular germ cell tumors (GCTs). CTC detection was associated with clinical stage, non-seminomatous GCTs, and elevated serum levels of $\alpha$-fetoprotein, human chorionic gonadotropic, and lactate dehydrogenase. Furthermore, 14/122 (11.5\%) of patients had detectable CTCs in peripheral blood, while 12/19 (63\%) of patients had detectable CTCs in testicular vein blood. While these preliminary findings are promising, additional larger trials are needed in these tumor types to better define the future role of CTC analysis in these cancers.

\section{SUMMARY AND FUTURE DIRECTIONS}

Whereas the majority of early CTC studies in GU cancer were focused on identification and enumeration - an end point with clinically important prognostic and predictive value-a growing emphasis now is being placed on molecular characterization of the tumor cells. As identification, recovery, and characterization become more accurate and cost effective, it will be important to determine whether the molecular profiles of CTCs provide information that can be used as a surrogate for tumor tissue, or whether in some cases CTCs provide information exceeding that available from biopsies (e.g., reflecting new drivers of resistance and progression). Gene rearrangements, translocations, differences in receptor expression and localization, and splice variations have all been successfully assayed in CTCs, and the molecular profiles derived from these liquid biopsies ultimately will offer utility in directing targeted therapy and selecting patients for appropriate clinical trials.

Future CTC studies in GU and other malignancies also will need to be integrated with rapidly emerging technologies for isolating and analyzing cell-free circulating tumor DNA (ctDNA), which is released from dying cells in primary tumors, metastases, and CTCs. Collection, shipping, and isolation of ctDNA are relatively straightforward and qPCR or NGS can be used to monitor cancer progression or emergence of new driver mutations (68). For example, through the use of ctDNA sequencing technology in the setting of CRPC, Lallous et al. (69) identified four single AR mutations and five mutation combinations associated with CRPC, which could be relevant to prognosis and therapy. In non-GU malignancies, ctDNA has demonstrated capacity as an accurate biomarker for extent of surgical resection and disease relapse (70) as well as a means of detecting therapeutically relevant DNA mutations in both the pre- and postsurgical settings (71). Just as CTC fragments were found predictive of prostate cancer recurrence, ctDNA offers a useful biomarker of residual disease or early disease recurrence and continues to be explored clinically with evolving applications $(19,72)$. An ongoing clinical trial, NCT02771769, is examining the utility of ctDNA in men with elevated PSA undergoing prostate biopsy to determine if copy number instability correlates with prostate cancer diagnosis and may reshape the landscape of prostate cancer screening (http://clinicaltrials.gov). As with CTCs, ctDNA analysis presents important new questions: for example, ctDNA represents the genome of dying tumor cells (as well as any other dying nontumor cells), so the genomes of treatment-resistant cells may not be fully represented or detectable. Moreover, whereas CTCs allow 
multiparametric analysis of DNA, RNA, and proteins, ctDNA by definition yields just genomic information. Our own work in this field (unpublished data) suggests that-not unexpectedly-CTCderived and cell-free-derived DNA may yield somatic profiles that do not fully overlap and may ultimately complement each other as liquid biopsy methods. Still other blood-based markers now emerging include tumor cell-derived exosomes (73) and epigenetic profiling of ctDNA $(74,75)$. The future of "liquid

\section{REFERENCES}

1. Ashworth T. A case of cancer in which cells similar to those in the tumors were seen in the blood after death. Aust Med J (1869) 14:146-7.

2. Siegel RL, Miller KD, Jemal A. Cancer statistics. CA Cancer J Clin (2016) 66:7-30. doi:10.3322/caac.21332

3. Hu B, Rochefort H, Goldkorn A. Circulating tumor cells in prostate cancer. Cancers (Basel) (2013) 5:1676-90. doi:10.3390/cancers5041676

4. CELLSEARCH ${ }^{\circledR}$ System Overview | CELLSEARCH ${ }^{\circledR}$. (2016). Available from: https://www.cellsearchctc.com/product-systems-overview/cellsearchsystem-overview

5. Nagrath S, Sequist LV, Maheswaran S, Bell DW, Irimia D, Ulkus L, et al. Isolation of rare circulating tumour cells in cancer patients by microchip technology. Nature (2007) 450:1235-9. doi:10.1038/nature06385

6. Stott SL, Lee RJ, Nagrath S, Yu M, Miyamoto DT, Ulkus L, et al. Isolation and characterization of circulating tumor cells from patients with localized and metastatic prostate cancer. Sci Transl Med (2010) 2:25ra23. doi:10.1126/ scitranslmed.3000403

7. Karabacak NM, Spuhler PS, Fachin F, Lim EJ, Pai V, Ozkumur E, et al. Microfluidic, marker-free isolation of circulating tumor cells from blood samples. Nat Protoc (2014) 9:694-710. doi:10.1038/nprot.2014.044

8. Xu T, Lu B, Tai Y-C, Goldkorn A. A cancer detection platform which measures telomerase activity from live circulating tumor cells captured on a microfilter. Cancer Res (2010) 70:6420-6. doi:10.1158/0008-5472.CAN10-0686

9. Kolostova K, Broul M, Schraml J, Cegan M, Matkowski R, Fiutowski M, et al. Circulating tumor cells in localized prostate cancer: isolation, cultivation in vitro and relationship to T-stage and Gleason score. Anticancer Res (2014) 34:3641-6.

10. Qin X, Park S, Duffy SP, Matthews K, Ang RR, Todenhöfer T, et al. Size and deformability based separation of circulating tumor cells from castrate resistant prostate cancer patients using resettable cell traps. Lab Chip (2015) 15:2278-86. doi:10.1039/c5lc00226e

11. Vona G, Sabile A, Louha M, Sitruk V, Romana S, Schütze K, et al. Isolation by size of epithelial tumor cells : a new method for the immunomorphological and molecular characterization of circulating tumor cells. Am J Pathol (2000) 156:57-63. doi:10.1016/S0002-9440(10)64706-2

12. The DEPArray System. Available from: http://www.siliconbiosystems.com/ deparray-system (accessed 2016)

13. Gupta V, Jafferji I, Garza M, Melnikova VO, Hasegawa DK, Pethig R, et al. ApoStream $\left({ }^{\mathrm{TM}}\right)$, a new dielectrophoretic device for antibody independent isolation and recovery of viable cancer cells from blood. Biomicrofluidics (2012) 6:24133. doi:10.1063/1.4731647

14. Friedlander TW, Ngo VT, Dong H, Premasekharan G, Weinberg V, Doty $\mathrm{S}$, et al. Detection and characterization of invasive circulating tumor cells derived from men with metastatic castration-resistant prostate cancer. Int J Cancer (2014) 134:2284-93. doi:10.1002/ijc.28561

15. Osmulski P, Mahalingam D, Gaczynska ME, Liu J, Huang S, Horning AM, et al. Nanomechanical biomarkers of single circulating tumor cells for detection of castration resistant prostate cancer. Prostate (2014) 74:1297-307. doi:10.1002/pros.22846

16. Epic Sciences. Available from: http://www.epicsciences.com/what-we-do/ technology-overview (accessed 2016).

17. Campton DE, Ramirez AB, Nordberg JJ, Drovetto N, Clein AC, Varshavskaya $\mathrm{P}$, et al. High-recovery visual identification and single-cell retrieval of circulating tumor cells for genomic analysis using a dual-technology platform biopsy" therefore likely involves using all of these methods and better defining their respective utility in clinical settings (76).

\section{AUTHOR CONTRIBUTIONS}

$\mathrm{CH}$ and $\mathrm{DZ}$ assisted in researching, writing manuscript, and constructing associated figures. AG supervised work and assisted in research, writing, editing, and formatting of manuscript.

integrated with automated immunofluorescence staining. BMC Cancer (2015) 15:360. doi:10.1186/s12885-015-1383-x

18. Davis JW, Nakanishi H, Kumar VS, Bhadkamkar VA, McCormack R, Fritsche HA, et al. Circulating tumor cells in peripheral blood samples from patients with increased serum prostate specific antigen: initial results in early prostate cancer. J Urol (2008) 179:2187-91; discussion 2191. doi:10.1016/ j.juro.2008.01.102

19. Pal SK, He M, Wilson T, Liu X, Zhang K, Carmichael C, et al. Detection and phenotyping of circulating tumor cells in high-risk localized prostate cancer. Clin Genitourin Cancer (2015) 13:130-6. doi:10.1016/j.clgc.2014.08.014

20. Goodman OB Jr, Symanowski JT, Loudyi A, Fink LM, Ward DC, Vogelzang NJ. Circulating tumor cells as a predictive biomarker in patients with hormone-sensitive prostate cancer. Clin Genitourin Cancer (2011) 9:31-8. doi:10.1016/j.clgc.2011.04.001

21. Okegawa $T$, Nutahara K, Higashihara E. Immunomagnetic quantification of circulating tumor cells as a prognostic factor of androgen deprivation responsiveness in patients with hormone naive metastatic prostate cancer. J Urol (2008) 180:1342-7. doi:10.1016/j.juro.2008.06.021

22. Resel Folkersma L, San José Manso L, Galante Romo I, Moreno Sierra J, Olivier Gómez C. Prognostic significance of circulating tumor cell count in patients with metastatic hormone-sensitive prostate cancer. Urology (2012) 80:1328-32. doi:10.1016/j.urology.2012.09.001

23. Goodman OB Jr, Fink LM, Symanowski JT, Wong B, Grobaski B, Pomerantz $\mathrm{D}$, et al. Circulating tumor cells in patients with castration-resistant prostate cancer baseline values and correlation with prognostic factors. Cancer Epidemiol Biomarkers Prev (2009) 18:1904-13. doi:10.1158/1055-9965.EPI08-1173

24. de Bono JS, Scher HI, Montgomery RB, Parker C, Miller MC, Tissing H, et al. Circulating tumor cells predict survival benefit from treatment in metastatic castration-resistant prostate cancer. Clin Cancer Res (2008) 14:6302-9. doi:10.1158/1078-0432.CCR-08-0872

25. Danila DC, Heller G, Gignac GA, Gonzalez-Espinoza R, Anand A, Tanaka E, et al. Circulating tumor cell number and prognosis in progressive castration-resistant prostate cancer. Clin Cancer Res (2007) 13:7053-8. doi:10.1158/1078-0432.CCR-07-1506

26. Scher HI, Jia X, de Bono JS, Fleisher M, Pienta KJ, Raghavan D, et al. Circulating tumour cells as prognostic markers in progressive, castration-resistant prostate cancer: a reanalysis of IMMC38 trial data. Lancet Oncol (2009) 10:233-9. doi:10.1016/S1470-2045(08)70340-1

27. Olmos D, Arkenau HT, Ang JE, Ledaki I, Attard G, Carden CP, et al. Circulating tumour cell (CTC) counts as intermediate end points in castration-resistant prostate cancer (CRPC): a single-centre experience. Ann Oncol (2009) 20:27-33. doi:10.1093/annonc/mdn544

28. Okegawa T, Itaya N, Hara H, Tambo M, Nutahara K. Circulating tumor cells as a biomarker predictive of sensitivity to docetaxel chemotherapy in patients with castration-resistant prostate cancer. Anticancer Res (2014) 34:6705-10.

29. Goldkorn A, Ely B, Quinn DI, Tangen CM, Fink LM, Xu T, et al. Circulating tumor cell counts are prognostic of overall survival in SWOG S0421: a phase III trial of docetaxel with or without atrasentan for metastatic castration-resistant prostate cancer. J Clin Oncol (2014) 32:1136-42. doi:10.1200/ JCO.2013.51.7417

30. Goldkorn A, Ely B, Tangen CM, Tai YC, Xu T, Li H, et al. Circulating tumor cell telomerase activity as a prognostic marker for overall survival in SWOG 0421: a phase III metastatic castration resistant prostate cancer trial. Int J Cancer (2015) 136:1856-62. doi:10.1002/ijc.29212 
31. Scher HI, Heller G, Molina A, Attard G, Danila DC, Jia X, et al. Circulating tumor cell biomarker panel as an individual-level surrogate for survival in metastatic castration-resistant prostate cancer. J Clin Oncol (2015) 33:1348-55. doi:10.1200/JCO.2014.55.3487

32. Sweeney CJ, Chen YH, Carducci M, Liu G, Jarrard DF, Eisenberger M, et al. Chemohormonal therapy in metastatic hormone-sensitive prostate cancer. N Engl J Med (2015) 373:737-46. doi:10.1056/NEJMoa1503747

33. James ND, Sydes MR, Clarke NW, Mason MD, Dearnaley DP, Spears MR, et al. Addition of docetaxel, zoledronic acid, or both to first-line longterm hormone therapy in prostate cancer (STAMPEDE): survival results from an adaptive, multiarm, multistage, platform randomised controlled trial. Lancet Lond Engl (2016) 387:1163-77. doi:10.1016/S0140-6736(15) 01037-5

34. Yu EY, Li H, Higano CS, Agarwal N, Pal SK, Alva A, et al. SWOG S0925: a randomized phase II study of androgen deprivation combined with cixutumumab versus androgen deprivation alone in patients with new metastatic hormone-sensitive prostate cancer. J Clin Oncol (2015) 33:1601-8. doi:10.1200/JCO.2014.59.4127

35. Goldkorn A, Plets M, Agarwal N, Hussain M, Lara P. Circulating tumor cells (CTCs) in SWOG S1216: a phase 3 multicenter trial in metastatic hormone sensitive prostate cancer (mHSPC). J Clin Oncol (2016) 34 (suppl; abstr 11516).

36. Ma X, Xiao Z, Li X, Wang F, Zhang J, Zhou R, et al. Prognostic role of circulating tumor cells and disseminated tumor cells in patients with prostate cancer: a systematic review and meta-analysis. Tumour Biol (2014) 35:5551-60. doi:10.1007/s13277-013-1279-9

37. Shaffer DR, Leversha MA, Danila DC, Lin O, Gonzalez-Espinoza R, Gu B, et al. Circulating tumor cell analysis in patients with progressive castrationresistant prostate cancer. Clin Cancer Res (2007) 13:2023-9. doi:10.1158/10780432.CCR-06-2701

38. Attard G, Swennenhuis JF, Olmos D, Reid AH, Vickers E, A'Hern R, et al. Characterization of ERG, AR and PTEN gene status in circulating tumor cells from patients with castration-resistant prostate cancer. Cancer Res (2009) 69:2912-8. doi:10.1158/0008-5472.CAN-08-3667

39. Antonarakis ES, Lu C, Wang H, Luber B, Nakazawa M, Roeser JC, et al. $\mathrm{AR}-\mathrm{V} 7$ and resistance to enzalutamide and abiraterone in prostate cancer. N Engl J Med (2014) 371:1028-38. doi:10.1056/NEJMoa1315815

40. Scher HI, Lu D, Schreiber NA, Louw J, Graf RP, Vargas HA, et al. Association of AR-V7 on circulating tumor cells as a treatment-specific biomarker with outcomes and survival in castration-resistant prostate cancer. JAMA Oncol (2016) 2:1441-9. doi:10.1001/jamaoncol.2016.1828

41. Miyamoto DT, Lee RJ, Stott SL, Ting DT, Wittner BS, Ulman M, et al. Androgen receptor signaling in circulating tumor cells as a marker of hormonally responsive prostate cancer. Cancer Discov (2012) 2:995-1003. doi:10.1158/2159-8290.CD-12-0222

42. Reyes EE, VanderWeele DJ, Isikbay M, Duggan R, Campanile A, Stadler WM, et al. Quantitative characterization of androgen receptor protein expression and cellular localization in circulating tumor cells from patients with metastatic castration-resistant prostate cancer. J Transl Med (2014) 12:313. doi:10.1186/s12967-014-0313-z

43. Crespo M, van Dalum G, Ferraldeschi R, Zafeiriou Z, Sideris S, Lorente D, et al. Androgen receptor expression in circulating tumour cells from castration-resistant prostate cancer patients treated with novel endocrine agents. Br J Cancer (2015) 112:1166-74. doi:10.1038/bjc.2015.63

44. Darshan MS, Loftus MS, Thadani-Mulero M, Levy BP, Escuin D, Zhou XK, et al. Taxane-induced blockade to nuclear accumulation of the androgen receptor predicts clinical responses in metastatic prostate cancer. Cancer Res (2011) 71:6019-29. doi:10.1158/0008-5472.CAN-11-1417

45. Punnoose EA, Ferraldeschi R, Szafer-Glusman E, Tucker EK, Mohan S, Flohr P, et al. PTEN loss in circulating tumour cells correlates with PTEN loss in fresh tumour tissue from castration-resistant prostate cancer patients. Br J Cancer (2015) 113:1225-33. doi:10.1038/bjc.2015.332

46. Miyamoto DT, Zheng Y, Wittner BS, Lee RJ, Zhu H, Broderick KT, et al. RNA-Seq of single prostate CTCs implicates noncanonical Wnt signaling in antiandrogen resistance. Science (2015) 349:1351-6. doi:10.1126/science. aab0917

47. Jiang R, Lu YT, Ho H, Li B, Chen JF, Lin M, et al. A comparison of isolated circulating tumor cells and tissue biopsies using whole-genome sequencing in prostate cancer. Oncotarget (2015) 6:44781-93. doi:10.18632/ oncotarget.6330
48. Lohr JG, Adalsteinsson VA, Cibulskis K, Choudhury AD, Rosenberg M, CruzGordillo $\mathrm{P}$, et al. Whole-exome sequencing of circulating tumor cells provides a window into metastatic prostate cancer. Nat Biotechnol (2014) 32:479-84. doi:10.1038/nbt.2892

49. Hodgkinson CL, Morrow CJ, Li Y, Metcalf RL, Rothwell DG, Trapani F, et al. Tumorigenicity and genetic profiling of circulating tumor cells in small-cell lung cancer. Nat Med (2014) 20:897-903. doi:10.1038/nm.3600

50. Yu M, Bardia A, Wittner BS, Stott SL, Smas ME, Ting DT, et al. Circulating breast tumor cells exhibit dynamic changes in epithelial and mesenchymal composition. Science (2013) 339:580-4. doi:10.1126/science.1228522

51. Gao D, Vela I, Sboner A, Iaquinta PJ, Karthaus WR, Gopalan A, et al. Organoid cultures derived from patients with advanced prostate cancer. Cell (2014) 159:176-87. doi:10.1016/j.cell.2014.08.016

52. Vidal SJ, Rodriguez-Bravo V, Quinn SA, Rodriguez-Barrueco R, Lujambio A, Williams E, et al. A targetable GATA2-IGF2 axis confers aggressiveness in lethal prostate cancer. Cancer Cell (2015) 27:223-39. doi:10.1016/ j.ccell.2014.11.013

53. Cegan M, Kolostova K, Matkowski R, Broul M, Schraml J, Fiutowski M, et al. In vitro culturing of viable circulating tumor cells of urinary bladder cancer. Int J Clin Exp Pathol (2014) 7:7164-71.

54. Gallagher DJ, Milowsky MI, Ishill N, Trout A, Boyle MG, Riches J, et al. Detection of circulating tumor cells in patients with urothelial cancer. Ann Oncol (2009) 20:305-8. doi:10.1093/annonc/mdn627

55. Okegawa T, Hayashi K, Hara H, Nutahara K, Higashihara E. Immunomagnetic quantification of circulating tumor cells in patients with urothelial cancer. Int J Urol (2010) 17:254-8. doi:10.1111/j.1442-2042.2010.02454.x

56. Naoe M, Ogawa Y, Morita J, Omori K, Takeshita K, Shichijyo T, et al. Detection of circulating urothelial cancer cells in the blood using the CellSearch system. Cancer (2007) 109:1439-45. doi:10.1002/cncr.22543

57. Flaig TW, Wilson S, van Bokhoven A, Varella-Garcia M, Wolfe P, Maroni P, et al. Detection of circulating tumor cells in metastatic and clinically localized urothelial carcinoma. Urology (2011) 78:863-7. doi:10.1016/ j.urology.2011.05.045

58. Anantharaman A, Friedlander T, Lu D, Krupa R, Premasekharan G, Hough J, et al. Programmed death-ligand 1 (PD-L1) characterization of circulating tumor cells (CTCs) in muscle invasive and metastatic bladder cancer patients. BMC Cancer (2016) 16:744. doi:10.1186/s12885-016-2758-3

59. Gazzaniga P, de Berardinis E, Raimondi C, Gradilone A, Busetto GM, De Falco E, et al. Circulating tumor cells detection has independent prognostic impact in high-risk non-muscle invasive bladder cancer. Int J Cancer (2014) 135:1978-82. doi:10.1002/ijc.28830

60. Gazzaniga P, Gradilone A, de Berardinis E, Busetto GM, Raimondi C, Gandini O, et al. Prognostic value of circulating tumor cells in nonmuscle invasive bladder cancer: a CellSearch analysis. Ann Oncol (2012) 23:2352-6. doi:10.1093/annonc/mdr619

61. Guzzo TJ, McNeil BK, Bivalacqua TJ, Elliott DJ, Sokoll LJ, Schoenberg MP. The presence of circulating tumor cells does not predict extravesical disease in bladder cancer patients prior to radical cystectomy. Urol Oncol (2012) 30:44-8. doi:10.1016/j.urolonc.2009.10.008

62. Rink M, Chun FK, Dahlem R, Soave A, Minner S, Hansen J, et al. Prognostic role and HER2 expression of circulating tumor cells in peripheral blood of patients prior to radical cystectomy: a prospective study. Eur Urol (2012) 61:810-7. doi:10.1016/j.eururo.2012.01.017

63. Alva A, Friedlander T, Clark M, Huebner T, Daignault S, Hussain M, et al. Circulating tumor cells as potential biomarkers in bladder cancer. J Urol (2015) 194:790-8. doi:10.1016/j.juro.2015.02.2951

64. Nel I, Gauler TC, Bublitz K, Lazaridis L, Goergens A, Giebel B, et al. Circulating tumor cell composition in renal cell carcinoma. PLoS One (2016) 11:e0153018. doi:10.1371/journal.pone.0153018

65. Bluemke K, Bilkenroth U, Meye A, Fuessel S, Lautenschlaeger C, Goebel S, et al. Detection of circulating tumor cells in peripheral blood of patients with renal cell carcinoma correlates with prognosis. Cancer Epidemiol Biomarkers Prev (2009) 18:2190-4. doi:10.1158/1055-9965.EPI-08-1178

66. Gradilone A, Iacovelli R, Cortesi E, Raimondi C, Gianni W, Nicolazzo C, et al. Circulating tumor cells and 'suspicious objects' evaluated through CellSearch ${ }^{\circledR}$ in metastatic renal cell carcinoma. Anticancer Res (2011) 31:4219-21.

67. Nastały P, Ruf C, Becker P, Bednarz-Knoll N, Stoupiec M, Kavsur R, et al. Circulating tumor cells in patients with testicular germ cell tumors. Clin Cancer Res (2014) 20:3830-41. doi:10.1158/1078-0432.CCR-13-2819 
68. Mullane SA, Van Allen EM. Precision medicine for advanced prostate cancer. Curr Opin Urol (2016) 26:231-9. doi:10.1097/MOU.0000000000 000278

69. Lallous N, Volik SV, Awrey S, Leblanc E, Tse R, Murillo J, et al. Functional analysis of androgen receptor mutations that confer anti-androgen resistance identified in circulating cell-free DNA from prostate cancer patients. Genome Biol (2016) 17:10. doi:10.1186/s13059-015-0864-1

70. Diehl F, Schmidt K, Choti MA, Romans K, Goodman S, Li M, et al. Circulating mutant DNA to assess tumor dynamics. Nat Med (2008) 14:985-90. doi:10.1038/nm.1789

71. Beaver JA, Jelovac D, Balukrishna S, Cochran RL, Croessmann S, Zabransky DJ, et al. Detection of cancer DNA in plasma of patients with early-stage breast cancer. Clin Cancer Res (2014) 20:2643-50. doi:10.1158/1078-0432. CCR-13-2933

72. Esposito A, Criscitiello C, Locatelli M, Milano M, Curigliano G. Liquid biopsies for solid tumors: understanding tumor heterogeneity and real time monitoring of early resistance to targeted therapies. Pharmacol Ther (2016) 157:120-4. doi:10.1016/j.pharmthera.2015.11.007

73. Huang X, Yuan T, Liang M, Du M, Xia S, Dittmar R, et al. Exosomal miR-1290 and miR-375 as prognostic markers in castration-resistant prostate cancer. Eur Urol (2015) 67:33-41. doi:10.1016/j.eururo.2014.07.035
74. Ulz P, Thallinger GG, Auer M, Graf R, Kashofer K, Jahn SW, et al. Inferring expressed genes by whole-genome sequencing of plasma DNA. Nat Genet (2016) 48:1273-8. doi:10.1038/ng.3648

75. Legendre C, Gooden GC, Johnson K, Martinez RA, Liang WS, Salhia B. Whole-genome bisulfite sequencing of cell-free DNA identifies signature associated with metastatic breast cancer. Clin. Epigenetics (2015) 7:100. doi:10.1186/s13148-015-0135-8

76. Alix-Panabières C, Pantel K. Clinical applications of circulating tumor cells and circulating tumor DNA as liquid biopsy. Cancer Discov (2016) 6:479-91 doi:10.1158/2159-8290.CD-15-1483

Conflict of Interest Statement: The authors declare that the research was conducted in the absence of any commercial or financial relationships that could be construed as a potential conflict of interest.

Copyright (c) 2017 Hugen, Zainfeld and Goldkorn. This is an open-access article distributed under the terms of the Creative Commons Attribution License (CC BY). The use, distribution or reproduction in other forums is permitted, provided the original author(s) or licensor are credited and that the original publication in this journal is cited, in accordance with accepted academic practice. No use, distribution or reproduction is permitted which does not comply with these terms. 